\title{
LudoEscola: a Gamificação como Ferramenta de Transformação do Espaço Escolar
}

\author{
Daniel de Sant'anna Martins1, Anderson Paulo da Silva1, Oberdan Alves de \\ Almeida Junior1, Silvana Cockles Crisanto do Nascimento2 \\ 1CESAR School - CEP 50030-220 - Recife - PE - Brazil \\ 2Secretaria de Educação e Cultura de PE - Secretaria Executiva de Educação \\ Profissional - 50.810-000 - Recife - PE - Brazil

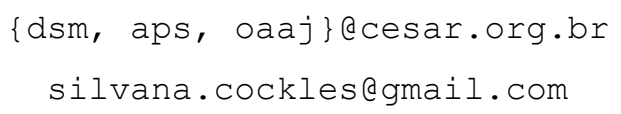

\begin{abstract}
In the current educational context, especially in high school, much is discussed about the lack of engagement and protagonism of students, and the difficulty of promoting them. In this practice, young people are invited to investigate problems of the school world, or opportunities for improvement, and to propose gamification interventions that can solve them. The initiative presents students with concepts, methods and examples of gamification so that they can inspire them to develop proposals for solutions and apply them in their daily lives. After the application of the practice was perceived a great commitment of the students in the activities of the school.
\end{abstract}

Resumo. No contexto educacional atual, principalmente no ensino médio, muito se discute sobre a falta de engajamento e do protagonismo dos estudantes, e a dificuldade de promovê-los. Nessa prática, os jovens são convidados a investigar problemas do universo escolar ou oportunidades de melhorias, e propor intervenções gamificadas que possam solucioná-los. A iniciativa apresenta aos estudantes conceitos, métodos e exemplos de gamificação para que possam inspirá-los a desenvolverem propostas de solução e aplicá-las em seu cotidiano. Após a aplicação da prática foi percebido um grande engajamento dos estudantes nas atividades da escola.

\section{Introdução}

Diversas são e metodologias que visam ressignificar os modelos educacionais. Do Construcionismo de Seymour Papert (1980) à Paulo Freire (1999) que afirmava que o educador precisa saber que "ensinar não é transferir conhecimento, mas criar as possibilidades para a sua produção ou a sua construção", todas dependem fundamentalmente da boa vontade dos educadores, mas principalmente do engajamento dos estudantes.

Na Escola Técnica Estadual Cícero Dias, acontece o NAVE - Núcleo Avançado em Educação - um programa de Ensino Médio Integrado Profissionalizante desenvolvido pelo Oi Futuro em parceria com as Secretarias de Estado de Educação do Rio de Janeiro 
e de Pernambuco, a escola pública de ensino médio se integra à cursos técnicos de tecnologias digitais - Programação de Jogos Digitais e Multimídia - desenvolvidos em parceria com o CESAR (Centro de Estudos e Sistemas Avançados do Recife), um centro de pesquisa e inovação sem fins lucrativos com sede na cidade de Recife, Pernambuco.

Nesse contexto, uma das disciplinas do do ensino médio dos cursos técnicos Projeto Integrador - teve como proposta no ano de 2017 promover o aprendizado através da oferta de diversas "micro-oficinas" optativas, com foco no desenvolvimento de projetos realizada pelos estudantes. A cada bimestre são oferecidas algumas dessas oficinas, com duração de três a quatro semanas, que integram os estudantes de ambos os cursos, agrupando-os de acordo com o interesse pessoal a partir do tema proposto. Uma dessas oficinas, intitulada "Gamificando a Vida", tem como preposto o ensino de conceitos, métodos e práticas de gamificação, capacitando os estudantes a pensar e desenvolverem soluções para situação problema encontrada no contexto escolar.

\section{Definindo Gamificação}

Inicialmente criado como método aplicado em programas de marketing para internet e contextos empresariais com a finalidade de motivar, engajar e fidelizar clientes e usuários (Zichermann e Cunningham, 2012), a gamificação, conforme o termo foi traduzido, pressupõe a utilização de elementos tradicionalmente encontrados nos jogos (como narrativa, sistemas de feedback, recompensas, conflitos, cooperatividade e competitividade, metas alcançáveis, regras claras, interatividade, dentre outros), em outras atividades e contextos que não são diretamente lúdicos.

A gamificação na verdade, vai bem além da simples implementação de técnicas de jogos em outros ambientes (Werbach e Hunter 2012). Podemos dizer que trata-se de um fenômeno emergente, que deriva da popularidade dos games, e de suas capacidades intrínsecas de motivar a ação, resolver problemas e potencializar aprendizagens nas diversas áreas do conhecimento e na vida dos indivíduos (Fardo 2013).

Seu objetivo principal é obter o mesmo grau de engajamento e motivação que normalmente encontra-se em jogadores envolvidos com jogos eletrônicos bem projetados. Além disso, serve também para promover comportamentos em seus usuários e/ou ensinar competências e habilidades específicas. Apesar de abundantes recursos interativos, nem sempre os mesmos são satisfatórios ou bem-sucedidos em sua implementação no meio educacional, por não se levar em conta o contexto em que o estudante está inserido, e por não colocá-lo como ponto central do design das experiências lúdicas definidas.

\section{Descrição da Experiência}

$\mathrm{Na}$ primeira aula, com aproximadamente quarenta estudantes de ambos os cursos, e cinquenta minutos de duração, o professor iniciou provocações e reflexões como: "Por que todo mundo deveria jogar?". Os estudantes trouxeram diversas respostas para essa questão, tais como: "porque é divertido", "porque me deixa feliz", "faz passar o tempo", entre outras. É importante ressaltar que não há de fato uma resposta correta. Neste momento, os estudantes são incentivados a refletirem sobre o assunto para despertar a curiosidade e engajamento. Após essa problematização inicial, foi feita uma exposição oral sobre a história dos jogos e sua aplicabilidade ao longo dos tempos.

Os jogos existem há milhares de anos, e no início não foram projetados com um sentido estrito à diversão ou para "passar o tempo", mas para tratar questões da vida, 
como cultura, religiosidade, etc. Segundo Huizinga (1971) "As grandes atividades arquetípicas da sociedade humana são, desde o início, inteiramente marcadas pelo jogo”, como exemplos, podemos destacar o jogo egípcio Senet, considerado por muitos um dos jogos mais antigos, que datam de mais ou menos 3 mil anos a.c. A palavra Senet significa "passagem" do espírito para uma nova vida após a morte (Teixeira, 2017). Um outro exemplo pertinente é documentado pelo filósofo grego Heródoto, onde ele descreve a história ocorrida há cerca de 3 mil anos do rei Atys da Lídia, que, motivado por uma enorme escassez de alimentos, fez o seu povo alternar entre alimentar-se em um dia e jogar jogos intensamente no outro, conseguindo assim, resistir à essa adversidade durante 18 anos (McGonigal, 2011). Atualmente a motivação para jogarmos mudou, segundo McGonigal (2011), o mundo está gastando mais de 3 bilhões de horas por semana com jogos. As pessoas estão buscando algo que a realidade não está oferecendo e os jogos estão suprindo esta necessidade. Para ela, a realidade está "quebrada" e os jogadores podem consertá-la.

Vale destacar que existem pesquisas e linhas teóricas que indicam que a experiência de jogar é gratificante justamente porque oferece desafios, pelo fato de convidar o jogador a um tipo de "trabalho árduo", impulsionando o desenvolvimento da criatividade, em que oportuniza formas de socialização que nos ajudam a constituir novos relacionamentos. "Jogar um jogo é a tentativa voluntária de superar obstáculos desnecessários" (Salen e Zimmerman, 2004). Jane McGonigal (2011) acrescenta que "os jogos nos desafiam com obstáculos voluntários e nos ajudam a usar melhor nossos pontos fortes pessoais". O fracasso no jogo não é algo negativo, e sim um combustível para o alcance do êxito, que potencializa o sentimento de realização. Também é importante ressaltar que a gamificação vem apresentando uma rápida difusão pela educação, aplicada como estratégia de ensino e aprendizagem, com o público jovem que conhece os vários conceitos de games, o que vem trazendo diversos resultados positivos (Sheldon 2012). Segundo Bem (2014), a área de educação é atualmente uma das maiores consumidoras de produtos gamificados, auxiliando o processo de aprendizagem de maneira mais lúdica, aumentando a motivação dos participantes. Silva (et al, 2015), por sua vez, comprova que a aplicação de atividades gamificadas na educação proporcionam aumento da motivação e do estímulo para a busca do conhecimento nos estudantes.

Para finalizar essa contextualização, o professor apresentou um vídeo da pesquisadora Jane McGonigal, "Jane McGonigal: Truths \& Myths in Gaming" [McGonigal 2012], que aborda e desmistifica alguns preconceitos sobre os jogos, como "as gerações que cresceram escutando que eles são uma perda de tempo e que estavam desperdiçando suas vidas ao passar horas jogando". Há na sociedade uma preocupação em relação ao vício e a violência, então levantou-se a questão para debate "Os jogos podem ser considerados vilões ou responsáveis?".

Posteriormente, na segunda aula, também de cinquenta minutos, assim como as demais, ocorreu uma exposição dialogada que mobilizou os estudantes a refletirem sobre o que é e o que não é gamificação. Utilizando-se de uma apresentação de slides que compartilhou reflexões de alguns especialistas sobre o assunto, estabeleceu-se o conceito de gamificação, que compreende "o uso de mecânicas de jogos e design de experiência para envolver e motivar [...] as pessoas para alcançar seus objetivos". Nesse itinerário de definição sobre o conceito fundamental da gamificação, foi destacado o fato de que não é possível reduzi-la ao simples ato de dar pontos, prêmios ou exibir um quadro com um ranking. Os estudantes compreenderam que esses elementos isolados não tem um grande 
impacto; é necessário avaliar o contexto que está sendo gamificado para a obtenção de bons resultados.

$\mathrm{Na}$ terceira aula, foi apresentado aos estudantes o framework Octalysis desenvolvido por Yu Kai-Chou - que é uma metodologia que sintetiza elementos basilares da motivação que todo ser humano possui ao jogar. Após fazer uma breve apresentação do Octalysis, o docente exibe o vídeo: "Gamification to improve our world yu-kai chou at tedxlausanne", no qual o autor descreve sua metodologia com exemplos. Depois da exibição do vídeo, o professor apresentou com maior ênfase os oito elementos do framework, que são:

1. Significado Épico e Chamado (Epic Meaning \& Calling) - o jogador acredita que está fazendo algo maior que ele mesmo. Ele foi o "escolhido" para fazer algo grandioso. Exemplos: Wikipedia, Jogos MMO (Massive Multiplayer Online, em português, Multijogador Massivo Online).

2. Desenvolvimento e Realização (Development \& Accomplishment) - o jogador é impulsionado a realizar avanços, progressos, desenvolver habilidades e superar desafios. Exemplos: Mudanças de níveis, desenvolvimento do personagem em jogos.

3. Empoderamento da Criatividade e Feedback (Empowerment of Creativity \& Feedback) - o jogador está envolvido num processo criativo no qual repetidamente tem de descobrir algo e tentar combinações diferentes. Exemplos: Lego, Pintar.

4. Propriedade e Posse (Ownership \& Possession) - o jogador é motivado por possuir alguma coisa e desejar torná-la melhor, ou possuir ainda mais. Exemplos: Acumular riqueza nos jogos, personalizar seu perfil ou avatar.

5. Influência Social e Pertencimento (Social Influence \& Relatedness) - o jogador é motivado por elementos sociais que influenciam as pessoas, incluindo orientação, aceitação, respostas sociais, companheirismo, bem como a competição e a inveja. Exemplos: Alcançar o mesmo nível no jogo (ou ultrapassar) porque um amigo está em um nível mais alto ou jogar um jogo porque todo mundo está jogando.

6. Escassez e Impaciência (Scarcity \& Impatience) - o jogador é motivado pelo desejo de algo que não pode ter. Exemplos: Jogos que pedem para voltar depois para ganhar uma recompensa ou venda de jogos para um público exclusivo.

7. Imprevisibilidade e Curiosidade (Unpredictability \& Curiosity) - o jogador é motivado por querer descobrir o que vai acontecer a seguir. Se ele não sabe o que vai acontecer, o seu cérebro está envolvido e pensa sobre isso muitas vezes. Exemplos: Jogos de loteria e assistir Séries.

8. Perda e Evasão (Loss \& Avoidance) - o jogador é motivado pela prevenção de algo negativo que possa ocorrer. Exemplo: Não desistir de continuar um jogo porque todo trabalho realizado seria perdido. 


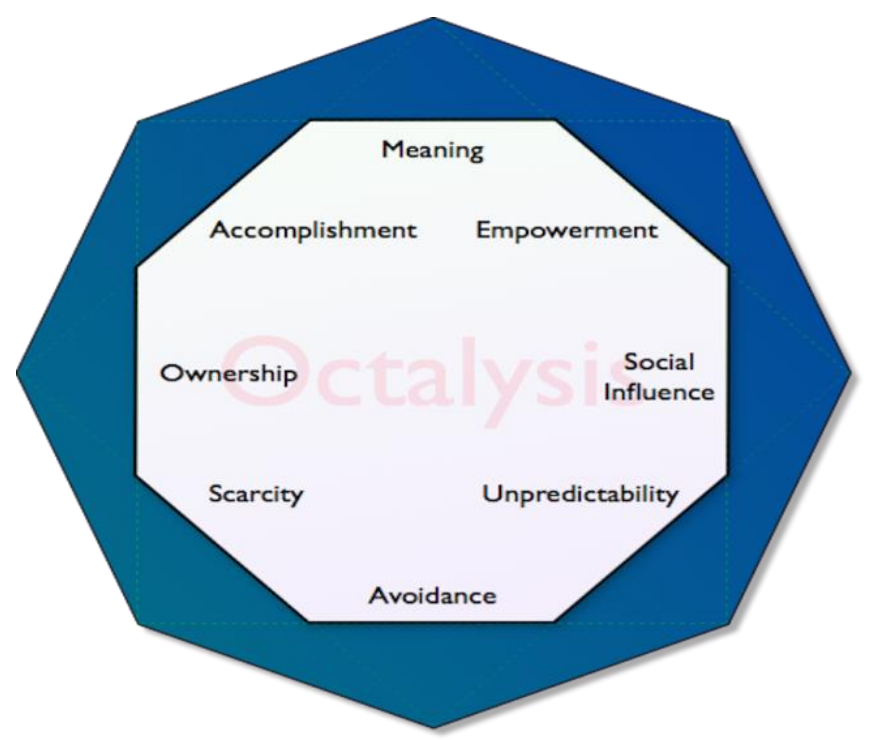

Figura 1: Diagrama da ferramenta Octalysis, baseado em Chou (2015).

Essa apresentação é seguida de exemplos de Gamificação, exibidos em alguns vídeos, destacando as estratégias e os elementos de jogos utilizados em cada situação; o aspecto inovador, o que torna cada um deles interessante e como eles engajam as pessoas em suas dinâmicas. É importante também perguntar aos estudantes, ao final de cada vídeo, quais elementos do framework podem ser observados. Todos os vídeos exibidos são da campanha The Fun Theory, promovida pela Volkswagen em 2010.

Com os estudantes inspirados e motivados, o próximo passo do professor é organizar a turma em times de cinco integrantes e convidando-los a investigar o espaço escolar. A ideia é encontrar desafios e oportunidades que podem ser aprimorados/solucionados, através de um projeto de intervenção gamificada, pelos estudantes. Foi organizado com os estudantes um roteiro com questões orientadoras para o passeio pela escola. Nesse roteiro de pesquisa, foram relacionados elementos de investigação, como por exemplo, as pessoas com as quais eles podem conversar (outros jovens, professores, cozinheiros, pessoal da limpeza, bibliotecária, coordenação, entre outras), e quais perguntas poderiam ser feitas buscando identificar questões problemáticas, etc.

Terminada a investigação, cada time criou uma proposta de intervenção gamificada que partiram das ideias levantadas durante a circulação pela escola, e mandatoriamente continham um ou mais elementos do framework Octalysis estudado nos encontros anteriores. Durante todo o processo, o professor conversou com cada time, apoiando-os na aplicação dessa metodologia, avaliando a viabilidade da proposta, principalmente no que se refere aos recursos e custos envolvidos; efetivamente, fazendo gestão e acompanhamento dos projetos. Vale salientar a importância do cuidado no momento da conversa com os times, para não permitir que eles descartem uma boa ideia. Cada projeto foi estruturado e detalhado em um documento (Google Docs, Microsoft Word, ou similar), com os nomes dos proponentes, um resumo da proposta, o públicoalvo, a indicação do problema que se busca resolver, a proposta de intervenção como solução, o prazo, os materiais necessários, os elementos basilares dos jogos que serão utilizados, os elementos norteadores do framework Octalysis e as referências.

A última etapa foi dedicada à implementação da intervenção por cada grupo. Em um primeiro momento, os times fizeram uma apresentação das propostas para toda a 
turma, a fim de que os demais pudessem conhecê-las. Posteriormente, os estudantes utilizaram a criatividade para desenvolver as intervenções propostas a partir dos materiais disponíveis. Uma vez criadas as intervenções, os jovens propuseram campanhas ou ações de mobilização (nos intervalos das aulas, por exemplo) e divulgaram para toda a escola suas propostas, e qual problema seria solucionado, incentivando assim a participação de todos os colegas.

Encerrando o percurso, depois que todos os projetos de intervenção gamificada foram realizados, o professor promoveu um encontro de avaliação e apropriação dos resultados; um momento para que todos identificassem as suas aprendizagens.

\section{Resultados obtidos: Projeto Caça ao Conhecimento Perdido}

O projeto Caça ao Conhecimento Perdido foi realizado em parceria com a coordenadora da biblioteca, que ajudou o time de estudantes na sua concepção e implementação em um evento interno da escola. Para estruturação do projeto, forneceu-se aos estudantes um documento norteador que continha a seguinte estrutura: 1) Título do projeto; 2) Proponentes; 3) Descrição do projeto, contendo ainda um Resumo, Público-alvo, Problema, Proposta da solução, Prazo para implementação do projeto, materiais necessários, Quais elementos dos jogos são usados no projeto, Quais elementos do framework Octalysis são utilizados; 4) Trabalhos futuros; e, 5) Referências. O documento segue abaixo exposto conforme proposto pelos estudantes.

Título do projeto: Caça ao Conhecimento Perdido.

Proponentes: Caio Henrique, Gabriel Augusto, Janderson Ferreira, Thiago Cesar e Vinnícius Rodrigo.

\section{Descrição do projeto}

Resumo: Caça ao Conhecimento Perdido é um projeto que visa transformar o espaço da biblioteca em um ambiente que promova novas formas de ressignificar a leitura e o uso interativo do espaço, para promover e resgatar o gosto pela mesma. Para isso, os estudantes são convidados a participar de um desafio que, ao completá-lo, serão destacados no quadro dos leitores do mês (com maior número de títulos lidos no período estabelecido) da biblioteca e poderão ganhar prêmios, como bombons, canetas, ingressos de cinema, entre outros. $\mathrm{O}$ desafio, dividido em 4 partes chamadas de trilha, consiste em enviar para os e-mails dos participantes, ou pistas postas dentro do próprio espaço de leitura, dicas de livros que eles devem ler. Exemplo: O livro que você deve ler está no corredor 4, o autor é Machado de Assis e na obra é narrada a história de um personagem chamado Bentinho que tinha ciúmes excessivos em relação a sua amada. O livro trará a pista para o próximo título.

Estes títulos passam por uma prévia curadoria, que pode estar associada a períodos literários estudados no componente curricular da área de linguagem ou apenas da leitura deleite, ou relacionados há alguma temática

Depois do participante encontrar o livro e lê-lo, este deverá fazer um resumo ou resenha e enviar para os coordenadores do projeto que validarão o material enviado. Após a averiguação, será encaminha uma nova dica para o próximo livro. E esse processo se repete até o $4^{\circ}$ livro (chamado de livro chave). Após o $4^{\circ}$ livro, o leitor deverá escrever uma pequena história contendo todos os principais personagens dos livros lidos para finalizar a trilha. Ganham os participantes que completarem mais rápido todas as trilhas. Para ter direito aos prêmios, o participante deve terminar em uma das 3 colocações. Além 
de prêmios, ele terá o nome divulgado no quadro da biblioteca como um dos leitores vencedores do desafio. este material será postado nas mídias da escola para ampla compartilhamento.

Público-alvo: Estudantes da Escola Técnica Estadual Cícero Dias - NAVE Recife.

Problema: Incentivo a leitura deleite e clássica.

Proposta da solução: Criar um desafio, dividido em 4 partes chamadas de trilha, para um público máximo de 20 participantes. Será feito uma chamada para o desafio nas redes sociais da escola e nos quadros informativos contendo o link do formulário de inscrição. Após um período de duas semanas, será avaliada a quantidade de inscritos. Tendo um mínimo de 10 participantes, o desafio é iniciado. O desafio consiste na solução de um enigma através de pistas e, este sendo resolvido, leva o participante até um livro. Após a leitura do livro, o participante deverá fazer um resumo ou resenha e enviar para os coordenadores do projeto que verificará o material enviado. Se estiver tudo correto, será liberado um novo enigma. Esse processo se repete até o $4^{\circ}$ livro (chamado de livro chave). Após o $4^{\circ}$ livro, o leitor deverá escrever uma pequena história contendo todos os principais personagens dos livros lidos para finalizar a trilha. Ganham os participantes que completarem mais rápido todas as trilhas. Para ter direito aos prêmios, o participante deve terminar em uma das 3 colocações. Além de prêmios, ele terá o nome divulgado no quadro da biblioteca como um dos leitores vencedores do desafio.

Prazo para implementação do projeto: 2 meses.

Materiais necessários: Tecido TNT, E.V.A, Papel, Cola, Garrafas recicláveis, Copos plásticos, entre outros.

Quais elementos dos jogos são usados no projeto? Competição; Desafio; Diversão; Interatividade; Metas, Participação voluntária; Recompensa; Regras.

Quais elementos do framework Octalysis são utilizados? Significado épico e chamado; Desenvolvimento e Realização; Influência Social e Pertencimento e Imprevisibilidade e Curiosidade.

Trabalhos futuros: Resgatar o clube de leitura da escola e levar o projeto para outras escolas, adaptando a realidade das outras escolas.

Referências: TOIA, Brinquedos. Caça ao Tesouro. 2005. $<$ https://www.ludopedia.com.br/jogo/caca-ao-tesouro-i\#>. Acesso em: 05 nov. 2018. 


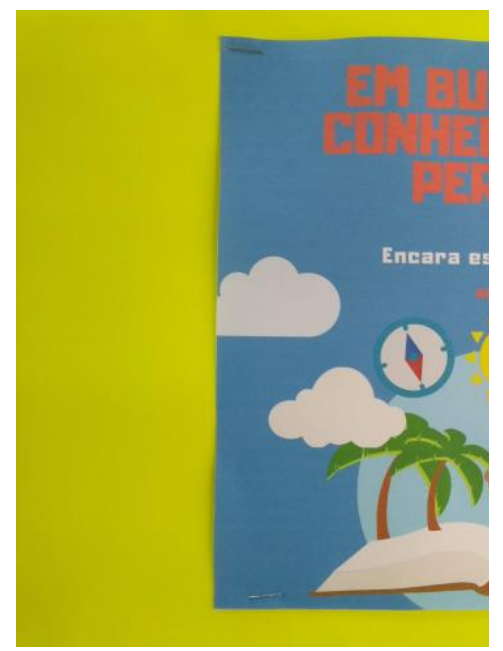

Figura 2: Identidade visual do projeto Caça ao Conhecimento Perdido.

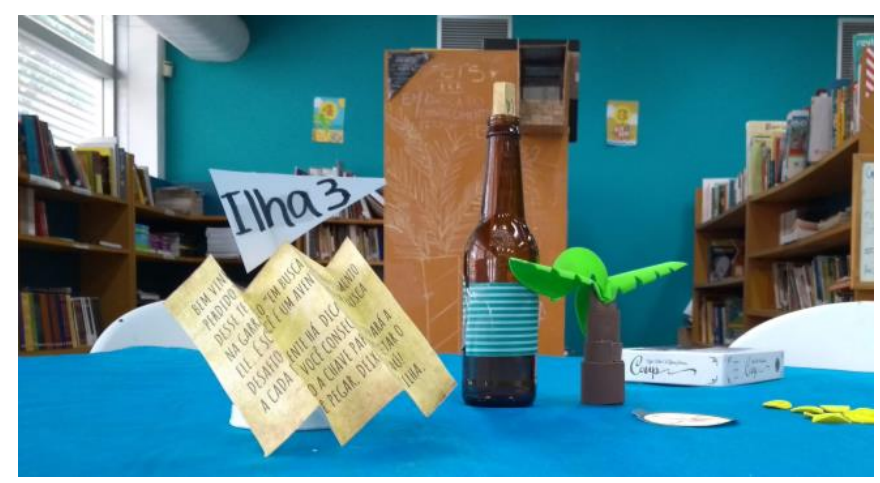

Figura 3: Elementos do projeto Caça ao Conhecimento Perdido.

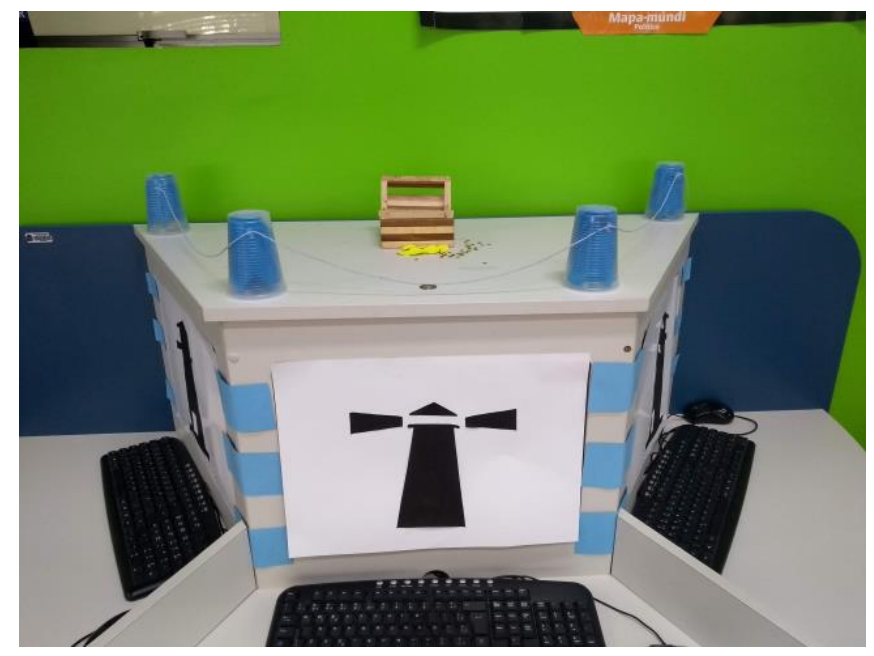

Figura 4: Elementos do projeto Caça ao Conhecimento Perdido. 


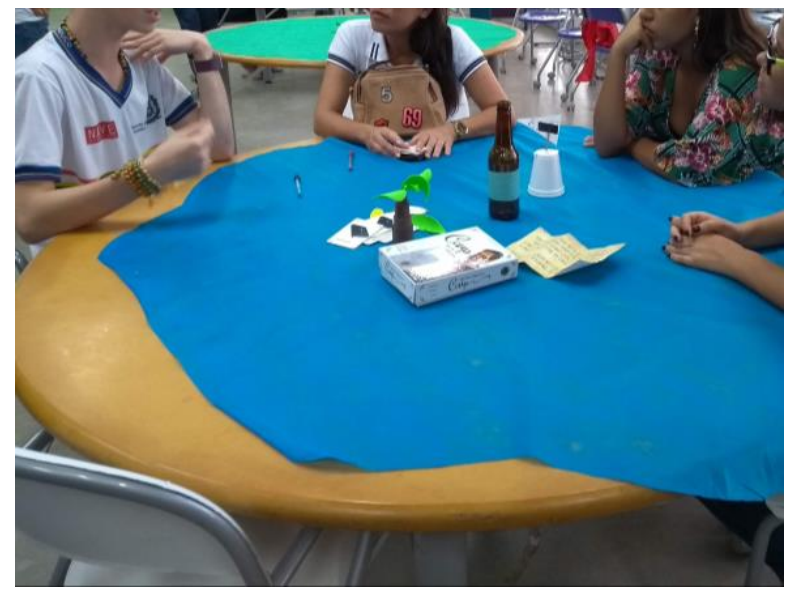

Figura 5: Usuários interagindo com o projeto Caça ao Conhecimento Perdido e seu aplicador.

\section{Conclusão}

A escola é um espaço social e possui recursos que são compartilhados (salas de aula, biblioteca, refeitório, quadra, etc.) sendo alguns deles mal utilizados ou subutilizados. Além disso, a convivência cotidiana faz surgir outras questões relevantes, como bullying, baixo desempenho escolar, evasão, entre outros. Essa atividade oportunizou que os estudantes desenvolvessem uma leitura crítica sobre o ambiente escolar, compreendendoo como lugar social em sua complexidade, preparando o jovem para identificar as suas possibilidades de agência nesse espaço.

O percurso da prática convidou os estudantes a criarem propostas de intervenção na escola norteadas por um framework de gamificação, para impactar positivamente esse microcosmo. A proposta de utilizar estratégias de gamificação foi profícua, pois engajou tanto a turma que propôs a intervenção quanto toda a comunidade escolar. A atividade gerada em conjunto com a biblioteca da escola mobilizou os estudantes de forma autônoma e alcançou uma projeção de destaque dentro de um evento escolar, já que diversos visitantes interagiram e elogiaram a mesma.

Com o auxílio da metodologia, os jovens se tornaram mais engajados, sentiramse desafiados e aprenderam que o fracasso não é negativo em si, mas sim uma motivação para se aperfeiçoar e tentar outras vezes.

\section{Referências}

Bem, R. F. S. (2014). Projeto ludus: uma metodologia gamificada de gerenciamento de projetos 2014. 73 f. Dissertação de Mestrado em Design - Departamento de Design, Universidade Federal de Pernambuco, Recife.

Burke, B. (2016). Gamify: How gamification motivates people to do extraordinary things. Routledge.

Chou, Y. K. (2015). Actionable gamification: Beyond points, badges, and leaderboards. Fremont, CA: Octalysis Group.

Chou, Y. K. (2015). Octalysis - The Complete Gamification Framework. Gamification \& Behavioral Design. Available from: https://yukaichou.com/gamification- 
examples/octalysis-complete-gamification-framework/. [Accessed 01 November 2018].

Fardo, M. L. (2013). A Gamificação Aplicada em Ambientes de Aprendizagem. Novas Tecnologias na Educação. CINTED-UFRGS. V.11, nº 1, julho.

Huizinga, J. (1971). Homo ludens: o jogo como elemento da cultura. Editora da Universidade de S. Paulo, Editora Perspectiva.

Mcgonigal, J. (2011). Reality Is Broken: Why Games Make Us Better And How They Can Change The World. Penguin.

Mcgonigal, J. (2012). Jane McGonigal: Truths \& Myths in Gaming. Big Think. Available from: https://www.youtube.com/watch?v=ZJ7uaD1YVmo. [Accessed 01 November 2018].

Salen, K., Zimmerman, E. (2004). Rules of play: Game design fundamentals. MIT press.

Sheldon, L. (2012). The Multiplayer Classroom: Designing Coursework as a Game, Boston, MA: Cengage Learning.

Silva, A. P., Martinz, V. F.; Dutra, C., Machado, T. L. A., Araújo, L. F. A. - Gamificação para Melhoria do Engajamento no Ensino Médio Integrado. Centro de Estudos em Sistemas Avançados do Recife, CESAR, Brasil. 2015.

Teixeira, R. E. C. (2017). Matemática Recreativa: Dados Para Todos Os Gostos. Atlântico Expresso, P. 17-17.

Werbach, K. e Hunter, D. (2012). For The Win: How Game Thinking Can Revolutionize Your Business. Filadélfia, Pensilvânia: Wharton Digital Press, 2012.

Zichermann, G. e Cunningham, C. (2011). Gamification by design: Implementing game mechanics in web and mobile apps. "O'Reilly Media, Inc.". 